\title{
Adsorption and Transport of Methane in Landfill Cover Soil Amended with Waste-Wood Biochars
}

\author{
Bala Yamini Sadasivam \\ Graduate Research Assistant, University of Illinois at Chicago, Department of Civil and \\ Materials Engineering, 842 West Taylor Street, Chicago, IL 60607, USA, e-mail: \\ bsadas2@uic.edu
}

Krishna R. Reddy

Professor, University of Illinois at Chicago, Department of Civil and Materials Engineering, 842

West Taylor Street, Chicago, IL 60607, USA, e-mail: kreddy@ uic.edu (Corresponding author)

\author{
Revised manuscript submitted to: \\ Journal of Environmental Management
}

April 19, 2015 


\section{ABSTRACT}

The natural presence of methane oxidizing bacteria (MOB) in landfill soils can stimulate the biochemical oxidation of $\mathrm{CH}_{4}$ to $\mathrm{CO}_{2}$ and $\mathrm{H}_{2} \mathrm{O}$ under suitable environmental conditions. This mechanism can be enhanced by amending the landfill cover soil with organic materials such as biochars that are recalcitrant to biological degradation and are capable of adsorbing $\mathrm{CH}_{4}$ while facilitating the growth and activity of MOB within their porous structure. Several series of batch and small-scale column tests were conducted to quantify the $\mathrm{CH}_{4}$ sorption and transport properties of landfill cover soil amended with four types of waste hardwood biochars under different levels of amendment percentages (2, 5 and $10 \%$ by weight), exposed $\mathrm{CH}_{4}$ concentrations $(0-1 \mathrm{kPa})$, moisture content (dry, 25\% and 75\% water holding capacity), and temperature $\left(25,35\right.$ and $\left.45^{\circ} \mathrm{C}\right)$. The linear forms of the pseudo second-order kinetic model and the Langmuir isotherm model were used to determine the kinetics and the maximum $\mathrm{CH}_{4}$ adsorption capacity of cover materials. The maximum $\mathrm{CH}_{4}$ sorption capacity of dry biocharamended soils ranged from $1.03 \times 10^{-2}$ to $7.97 \times 10^{-2} \mathrm{~mol} \mathrm{~kg}^{-1}$ and exhibited a ten-fold increase compared to that of soil with $1.9 \times 10^{-3} \mathrm{~mol} \mathrm{~kg}^{-1}$. The isosteric heat of adsorption for soil was negative and ranged from -30 to $-118 \mathrm{~kJ} \mathrm{~mol}^{-1}$, while that of the biochar-amended soils was positive and ranged from $24-440 \mathrm{~kJ} \mathrm{~mol}^{-1}$. The $\mathrm{CH}_{4}$ dispersion coefficients for biocharamended soils obtained through predictive transport modeling indicated that amending the soil with biochar enhanced the methane transport rates by two orders of magnitude, thereby increasing their potential for enhanced exchange of gases within the cover system. Overall, the use of hardwood biochars as a cover soil amendment to reduce methane emissions from landfills appears to be a promising alternative to conventional soil covers.

Key Words: Biochar, methane adsorption, landfill cover soil, biocover, methane mitigation 


\section{Introduction}

Landfill gas (LFG) mainly comprises greenhouse gases (GHGs) such as $\mathrm{CH}_{4}$ and $\mathrm{CO}_{2}$ in equal volumetric ratio (50\% v/v) and are produced by the decomposition of waste under limited oxygen environments. LFG emissions significantly contribute to global warming and its associated negative impacts. $\mathrm{CH}_{4}$ is considered to be a much powerful GHG with a Global Warming Potential (GWP) of 28 over a 100 yr. time scale when compared to $\mathrm{CO}_{2}$ (IPCC 2013). Landfills are ranked third highest among the potential anthropogenic sources for $\mathrm{CH}_{4}$ emissions in the U.S. The use of engineering controls such as gas collection and flaring systems aim to achieve effective capture and re-use of methane as an energy source. The use of engineered, biobased cover systems in combination with collection systems during its active phase, or just the use of bio-based cover systems in case of an old and/or abandoned landfill, can help minimize the overall $\mathrm{CH}_{4}$ emissions. A holistic approach needs to be adopted for an effective design of bio-based cover system in which, considerable reduction in $\mathrm{CH}_{4}$ emissions can be achieved by a combination of both, adsorption as well as biochemical oxidation processes (Sadasivam and Reddy 2014).

The use of organic amendments to landfill cover soils enhances the $\mathrm{CH}_{4}$ oxidation rates and reduces the $\mathrm{CH}_{4}$ fluxes emitted from landfills (Park et al. 2004; Stern et al. 2007; Nikiema et al. 2007; Huber-Humer et al. 2008; Huber-Humer et al. 2009; Pederson et al. 2011; Scheutz et al. 2011; Roncato et al. 2012). Albeit the addition of organic rich compost amendments to landfill cover soils enhances the microbial methane oxidation capacity, exo-polymeric substances form over time within the cover system that clog the pores and hinder the diffusion of gases (Wilheusen et al. 2004; Hilger et al. 2000; Powelson et al. 2006). In order to design an efficient 
biocover system for methane emissions from landfills, a stable biocover material needs to be selected where the material has a high porosity with the capability to enhance the methane adsorption capacity as well as favor the growth of methanotrophs and promote the microbial methane oxidation process. Limited studies have been conducted that investigate such porous, organic amendments, which have a high potential for the adsorption of $\mathrm{CH}_{4}$ and also facilitate enhanced gas transport properties that can together increase the $\mathrm{CH}_{4}$ oxidation rates by minimizing the adverse impacts due to the clogging of pores (Sadasivam and Reddy, 2014).

Biochar is a porous, organic material produced by the pyrolysis or gasification of waste biomass (Lehmann and Joseph, 2009). The process of biomass conversion and the treatment conditions are based on the desired end product, which can be biofuel for energy (Lehmann, 2007) or biochar for the purpose of environmental management (Lal, 2004; Lehmann and Joseph, 2009). The physicochemical properties of biochars are controlled by the initial characteristics of the feedstock, reactor treatment conditions such as temperature and residence time and also the post-treatment processes (if any) such as activation (Lua et al. 2004; Boateng, 2007). The porosity and specific surface area of biochars are dictated by the highest treatment temperature (Brown et al. 2006) and post-processing such as activation (Zhang et al. 2004). The increased presence of micropores in biochars makes it highly preferable for gas adsorption purposes (Rouquerol et al. 1999). Biochars, when used as a soil amendment, have a high potential to increase the sorption ability of soils mainly due to their pyrogenic production process. Several studies that compared the sorption properties of pyrogenic and non-pyrogenic or fresh biomass have found that the sorption ability of pyrogenic substances such as biochars is a couple of orders of magnitude higher than that of fresh biomass (Baring et al. 2002; Huang et al. 2003; Nguyen et al. 2004). The highly porous structure of biochars was previously shown to 
favor the growth and activity of methanotrophs when amended to a cover soil and enhance the potential for increased methane oxidation (Reddy et al. 2014).

The purpose of this study is to investigate and compare the $\mathrm{CH}_{4}$ sorption and transport properties of four waste-wood derived biochars amended to landfill cover soil at varying percentages (2, 5 and $10 \%$ by weight) as opposed to that of soil when used solely as a cover material. The specific objectives of this study are to: (1) quantify the kinetic rate of $\mathrm{CH}_{4}$ adsorption and the maximum methane adsorption capacity of landfill cover soil and biocharamended landfill cover soils under three levels of moisture (dry, 25\%WHC and 75\%WHC) and temperature $\left(25^{\circ} \mathrm{C}, 35^{\circ} \mathrm{C}\right.$ and $\left.45^{\circ} \mathrm{C}\right)$; (2) determine the effects of moisture, temperature and biochar-amendment percentages on $\mathrm{CH}_{4}$ adsorption and transport; and (3) determine the effect of landfill gas (LFG) inflow rate and presence of moisture on the $\mathrm{CH}_{4}$ transport and diffusion through soil and biochar-amended soils. The results from this study can help identify the potential use of biochars as amendments to landfill soil with the aim of achieving effective methane mitigation.

\section{Materials and methods}

\subsection{Biochars and soil}

Four types of biochars produced from waste-wood were chosen for this study based on preliminary screening and tests conducted on seven waste-wood biochar types (Yargicoglu et al. 2015). The waste-wood biochars were obtained from Chip Energy Inc. (Goodfield, IL) in 5gallon buckets, and were stored in labeled, airtight containers. The biochars were produced by 
gasification using an updraft gasifier at a temperature of about $500^{\circ} \mathrm{C}$. The feedstock for all the biochars was hardwood either in the chipped or pelleted forms. The fine ash fraction of the pelleted hardwood was retained in the case of CW-WP1, whereas, the ash fraction was sieved in the case of CE-WP2. CE-AWP was made out pelleted hardwood and the biochar was allowed to age under room temperature in a sealed drum for 3 years prior to its use in this study. CE-AWP was made of hardwood chips. The photographs of biochars are presented in Figure 1 of the supplementary document. The cover soil for the biochar amendment studies was obtained from the top 12 inches of an intermediate cover area in a DeKalb County, IL landfill. The cover soil was sieved using a $2 \mathrm{~mm}$ mesh and the fraction of soil passing the sieve was homogenized and stored in plastic bags at $4^{\circ} \mathrm{C}$ prior to usage. All the test materials were autoclaved using a Napco ${ }^{\circledR}$ model 8000 -DSE autoclave at $121^{\circ} \mathrm{C}$ for $30 \mathrm{~min}$ for two consecutive days (Bennett et al. 2003) and were sealed at $22^{\circ} \mathrm{C}$ for 24 hours between autoclave treatments (Carter et al. 2007) prior to conducting adsorption experiments.

\subsection{Physicochemical characterization testing}

In this study, the physicochemical properties of soil and biochar-amended soils were characterized in accordance with specific ASTM methods. The test materials were characterized for pH (ASTM D 4972), moisture content (MC) (ASTM D2216), organic content (OC) (ASTM D2974 by Loss-on-Ignition), average particle size (ASTM D422), specific gravity (SG) (ASTM D854), water holding capacity (WHC) (ASTM D2980), and dry density (ASTM D2937). All the physical-chemical characterization tests were conducted in duplicate on the sterilized materials.

SEM images of soil and biochars were used to quantify the porosities using Particles (Pores) and 
Cracks Analysis System (PCAS) software (Liu et al., 2011). Elemental C was determined using Perkin Elmer Elemental Analyzer. Further details on the characterization test procedures can be found in Yargicoglu et al. (2015).

\subsection{Batch adsorption testing}

Batch adsorption tests were conducted to determine the methane adsorption capacity of soil and biochar-amended soils under different levels of MC, temperature and exposed methane concentrations. Sterilization was performed on the materials prior to the adsorption tests to eliminate microbial interference on methane adsorption during the tests. A total of $5 \mathrm{~g}$ of the test material was placed inside $250 \mathrm{ml}$ amber glass bottles and sealed tight using long sleeved rubber stoppers. Then, $10,25,40,50,75$, and $100 \mathrm{ml}$ of air from the headspace of the test units was replaced with respective volumes of synthetic landfill gas comprising $50 \% \mathrm{CH}_{4}$ and $50 \% \mathrm{CO}_{2}$ in order to achieve headspace $\mathrm{CH}_{4}$ concentrations of 2, 5, 8, 10, 15, and 20\% (v/v), respectively. Control test units were set up similar to the sample test units that did not include the adsorbents, to determine the initial $\mathrm{CH}_{4}$ headspace concentration (v/v) achieved for each experimental set. In order to determine the effects of biochar-amendment percentages on $\mathrm{CH}_{4}$ adsorption, three amendment levels $(2,5$ and $10 \% \mathrm{w} / \mathrm{w})$ were selected by mixing the appropriate mass of biochars to the soil, keeping the total mass of the amended cover material constant at $5 \mathrm{~g}$ for all the tests. To determine the effects of moisture content on the methane adsorption, test units were set up that followed the procedure above, but with the addition of measured volumes of de-ionized water using a calibrated pipette to achieve moisture levels of 25 and $75 \%$ with respect to the biochar's WHC based on dry weight. The temperature in the test units was maintained at $25^{\circ} \mathrm{C}$ 
and the $\mathrm{CH}_{4}$ gas pressure ranged from 0.15 to $1 \mathrm{KPa}$ for all the tests conducted to study the effects of MC on the adsorption of $\mathrm{CH}_{4}$ onto cover materials. A hydrometer water bath (Model $\mathrm{H}$ - 4239A) manufactured by Humboldt Co. was used to maintain the specified temperature conditions within the test units at the required preset levels of $35^{\circ} \mathrm{C}$ and $45^{\circ} \mathrm{C}$ to test the effects of temperature on methane adsorption. All the test units (including the controls) were placed in the water bath and allowed to acclimate to the respective preset temperature levels. A thermometer was used to ensure that the appropriate temperature conditions existed within the test units prior to the start of the tests. All the adsorption tests were conducted until the material's maximum adsorption capacity was achieved. Gas samples were collected at intervals until the equilibrium conditions were achieved.

\subsection{Column adsorption testing}

The column tests were conducted to assess the adsorption and transport characteristics of methane through the soil and biochar-amended soils. The tests were conducted under influent methane flow rates of 7.3, 5.4 and $3.1 \mathrm{ml} \mathrm{min}^{-1}$ and moisture levels of dry, $25 \%$ and $75 \%$ with

respect to the material's WHC. The tests were conducted using a Kontes brand Chromaflex ${ }^{\circledR}$ glass chromatography column (420870) measuring $2.5 \mathrm{~cm}$ in diameter and $30 \mathrm{~cm}$ in length. The columns were fitted with a bed support mesh screen, PTFE tubing, end connections, and screw caps. To control the influent methane gas flow rates and to monitor the effluent flow rates, flow meters (GF -8330-1001, Gilmont Instruments) were installed at both ends of the column. The glass column and the fittings were sterilized prior to filling it with the sterilized soil and biochar/soil mixes. The columns were filled with test materials in two $15 \mathrm{~cm}$ thick layers; light 
tamping followed the placement of each layer. For the tests conducted at different moisture levels, $25 \%$ and $75 \%$ of the biochar's WHC, a biochar stock was prepared with a known mass by adding a known volume of de-ionized water and used to fill the column as mentioned previously. For each test, synthetic landfill gas mixture comprising $5 \% \mathrm{CH}_{4}(\mathrm{v} / \mathrm{v}), 5 \% \mathrm{CO}_{2}(\mathrm{v} / \mathrm{v})$ and $90 \% \mathrm{~N}_{2}$ (v/v) was introduced through the column bottom at a pre-selected constant flow rate and the effluent flow rates were monitored. Gas samples were collected from the effluent sampling port at intervals until breakthrough was achieved.

\subsection{Gas sampling and analysis}

All the gas samples were collected using a BD $10 \mathrm{ml}$ louver lock syringe and non-coring needle fitted with a two-way plastic stop-cock. The sampling syringe, needle and stop-cock were sterilized to avoid bacterial contamination of the test units and the samples. Gas samples were then stored in evacuated $5 \mathrm{ml}$ glass vials and analyzed within 4 hours from the time of collection using an HP 6890 GC with FID and GS- Carbon Plot column. Prior to analyzing the gas samples, the GC was calibrated using ultra high purity methane standards $\left(0.1,1,5\right.$, and $\left.25 \% \mathrm{CH}_{4} \mathrm{v} / \mathrm{v}\right)$ and a calibration curve was developed to interpret $\mathrm{CH}_{4}$ concentrations of the samples.

\subsection{Statistical analysis}

Statistical Analysis System (SAS®) software, version 9.3, was used to perform all the statistical analyses on the data obtained from batch adsorption tests to determine if the sample means were statistically different by using the Tukey's analysis. Analysis of Variance (ANOVA) procedures 
were used to determine the significant differences between the data sets from the batch isotherm tests. All the statistical analyses were based on the assumption that the error is normally distributed and relatively constant at all treatment levels. The assumptions were validated using the Proc univariate procedure and the null hypothesis was tested for means at an alpha level of 0.05 .

\subsection{Batch adsorption modeling}

Based on the batch adsorption test results, adsorption kinetic parameters were obtained based on the methane adsorbed at various time periods using the plots of linear forms of Lagergren first-order and second-order models shown in Eqns. (1) and (2), respectively.

$$
\begin{aligned}
& \log \left(q_{e}-q_{t}\right)=\log q_{e}-\frac{k_{1}}{2.303} t \\
& \frac{t}{q_{t}}=\frac{1}{k_{2} q_{e}{ }^{2}}+\frac{1}{q_{e}} t
\end{aligned}
$$

where $\mathrm{q}_{\mathrm{t}}(\mathrm{mL} / \mathrm{kg})$ is the amount of methane and carbon dioxide adsorbed at time $\mathrm{t}(\mathrm{min}) ; \mathrm{k}_{1}$ $\left(\mathrm{min}^{-1}\right)$ is the rate constant of Lagergren first-order adsorption; $\mathrm{k}_{2}\left(\mathrm{~kg} \cdot \mathrm{mL}^{-1} \mathrm{~min}^{-1}\right)$ is the rate constant of pseudo second-order adsorption; and $\mathrm{q}_{\mathrm{e}}(\mathrm{mL} / \mathrm{kg})$ is the amount of $\mathrm{CH}_{4}$ adsorbed per mass of the material at equilibrium.

Linear forms of Langmuir and Freundlich adsorption isotherm models as shown in Eqns. (3) and (4), respectively, were used to fit the adsorption data obtained for all of the materials tested. 


$$
\begin{aligned}
& \frac{1}{q_{e}}=\frac{1}{Q^{0}}+\frac{1}{b Q^{0}} \frac{1}{C_{e}} \\
& \log q_{e}=\log K_{F}+\frac{1}{n} \log C_{e}
\end{aligned}
$$

where $\mathrm{C}_{\mathrm{e}}$ is the equilibrium concentration of the gas $(\mathrm{kPa}) ; \mathrm{q}_{\mathrm{e}}$ is the amount of $\mathrm{CH}_{4}$ adsorbed per mass of the material $(\mathrm{mol} / \mathrm{kg}) ; \mathrm{Q}^{0}$ is the mole amount of gas adsorbed per unit weight of adsorbent (mol/kg); b is a constant related to the affinity of binding sites $\left(\mathrm{kPa}^{-1}\right)$; and $\mathrm{K}_{\mathrm{F}}$ and $\mathrm{n}$ are Freundlich constants related to adsorption capacity (mol/kg) and adsorption intensity (unit less), respectively. $\mathrm{Q}^{\circ}$ and $\mathrm{b}$ are the Langmuir model parameters that were calculated from the slope and intercept of the straight lines of the plot of $1 / \mathrm{q}_{\mathrm{e}}$ versus $1 / \mathrm{C}_{\mathrm{e}}$, while $\mathrm{K}_{\mathrm{F}}$ and $\mathrm{n}$ are the Freundlich model parameters determined from the slope and intercept of linear plot of log $\mathrm{q}_{\mathrm{e}}$ versus $\log \mathrm{C}_{\mathrm{e}}$.

\subsection{Column adsorption and transport modeling}

For modeling the transport of $\mathrm{CH}_{4}$ through biochar columns, the linear sorption coefficient $\left(\mathrm{K}_{\mathrm{d}}\right)$ is calculated from the corresponding batch sorption experiments conducted on the biochars at low exposed $\mathrm{CH}_{4}$ concentartions $\left(<8 \% \mathrm{CH}_{4} \mathrm{v} / \mathrm{v}\right)$. The linear and non-kinetic sorption is assumed for the column tests; however, the nonlinear and kinetic sorption may be approriate to consider in the field scale cover systems. The one-dimensional advection-dispersion mass balance for a conservative substance is shown in Eqn. (5) below,

$$
\frac{\partial C}{\partial t}=D \frac{\partial^{2} C}{\partial x^{2}}-v \frac{\partial C}{\partial x}
$$


where $\mathrm{C}=$ solute concentration, $\left(\mathrm{mol} / \mathrm{m}^{3}\right) ; \mathrm{t}=$ time, $(\mathrm{min}) ; \mathrm{D}=$ hydrodynamic dispersion, $\left(\mathrm{m}^{2} / \mathrm{min}\right) ; v=$ average linear velocity, $(\mathrm{m} / \mathrm{min})$; and $\mathrm{x}=$ distance in the direction of flow, $(\mathrm{m})$.

$\frac{\partial S}{\partial t}$ is assumed to be the adsorption isotherm. In the case of linear sorption, this is given by Eqn. (6) below,

$\frac{\partial S}{\partial t}=\frac{\rho_{b}}{\eta} \frac{\partial\left(K_{d} C\right)}{\partial t}$

Eqn. (6) can be recognized as shown in Eqn. (7), below,

$\frac{\partial C}{\partial t}\left(1+\frac{\rho_{b}}{\eta} K_{d}\right)=D \frac{\partial^{2} C}{\partial x^{2}}-v \frac{\partial C}{\partial x}$

where

$$
R=1+\frac{\rho_{b}}{\eta} K_{d}
$$

where $\mathrm{R}=$ retardation factor (non-dimensional); $\rho_{\mathrm{b}}=$ bulk density of adsorbent $\left(\mathrm{kg} / \mathrm{m}^{3}\right) ; \mathrm{K}_{\mathrm{d}}=$ solid water distribution ratio $\left(\mathrm{m}^{3} / \mathrm{kg}\right)$; and $\eta=$ total porosity of the adsorbent. It should be noted that there is a possibility that a small fraction of methane is transferred from the gas phase to the liquid phase instead of directly sorbing to the biochar surface from the gas phase. However, the sorption of methane in gas phase directly onto the pore spaces of biochar was assumed to be more predominant than dissolution in this case since the solubility of methane in water is very low, with a value of $0.03 \mathrm{~mL} \mathrm{CH}_{4} / \mathrm{mL} \mathrm{H}_{2} \mathrm{O}$ at STP (Yamamoto et al. 1976).

The following initial and boundary conditions are applicable for the column experiments for this study:

$$
\begin{aligned}
& C(x, 0)=5 \%(v / v) \text { for } x \geq 0 \\
& C(0, t)=C_{0} \text { for } t \geq 0 \\
& C(\infty, t)=5 \%(v / v) \text { for } t \geq 0
\end{aligned}
$$

The solution to the advection-dispersion equation (7) is given as: 
$C=\frac{C_{0}}{2}\left[\operatorname{erfc}\left(\frac{L-v^{\prime} t}{2 \sqrt{D^{\prime} t}}\right)+\exp \left(\frac{v^{\prime} L}{D^{\prime}}\right) \operatorname{erfc}\left(\frac{L+v^{\prime} t}{2 \sqrt{D^{\prime} t}}\right)\right]$

where $v^{\prime}=v / R$ and $D^{\prime}=D / R$.

The solution derived in Eqn. (9) assumes that equilibrium exists between the solute concentration and the adsorbed phase surface concentration and the relationship is linear. The transport of methane through the adsorbent is modeled based on the assumption that the lateral dispersion of the gas is negligible, while accounting for the linear dispersion only. The methane breakthrough curves were modeled using MATLAB to compute the dispersion coefficients for the soil and biochar-amended soils.

\section{Results}

\subsection{Physicochemical Characterization Testing}

The physicochemical properties of soil and different biochar-amended soils are shown in Table 1. The $\mathrm{pH}$ of soil and different biochar-amended soils were neutral to slightly basic, ranging from $7.0-7.6$. The moisture content of the sterilized soil was $2.1 \%$ (d.w.) and was comparatively higher than that of the biochar-amended soils, which ranged from $0-1.3 \%$ (d.w.). The organic content of the cover soil was $0.8 \%$ (d.w.), while that of the biochar-amended soils was much higher. Notable, the amount of organic content increased steadily with an increase in the percentage of biochar amendment to the soil (Table 1). Sample S+10\%WP1 exhibited the highest level of organic content (14.5\% d.w.), followed closely by S+10\%WP2 (12.45\% d.w.). The magnitude of increase in organic content for the CE-AWP and CE-WC biochar amended soils was relatively lower that of the other two biochar types tested. 
The average soil particle size was much smaller $(0.03 \mathrm{~mm})$ compared to the biocharamended soil samples. In fact, the average particle size of the amended soil increased with an increase in the amendment percentages irrespective of the biochar type tested. CE-WC biochar amended samples had the highest average particle size, which ranged from $0.34-0.43 \mathrm{~mm}$, followed by CE-AWP amended soils, which ranged from $0.22-0.26 \mathrm{~mm}$. The average particle size of CE-WP2 amended soils were slightly lower than that of CE-AWP amended soils, with a range of $0.20-0.22 \mathrm{~mm}$. The CE-WP1 samples showed the lowest particle sizes among all the biochar-amended soils at different amendment percentages $(0.10-0.20 \mathrm{~mm})$. The specific gravity value for the soil was 2.59 and the addition of biochar to soil consistently decreased the specific gravity as the percentage of the biochar amendment increased, for all of the biochar types tested. The cover soil exhibited the least capacity to retain water within its pores as compared to biochar-amended soils.

The WHC of the biochar-amended soil samples increased as the amendment percentages increased for the four biochar types tested. The dry density of the soil was $1.89 \mathrm{~g} / \mathrm{cm}^{3}$ and the density of cover materials consistently decreased with the increase in the biochar-amendment to soil percentage irrespective of the biochar type that was tested. In general, the CE-WC amended soils had the lowest dry density, ranging from $1.24-1.61 \mathrm{~g} / \mathrm{cm}^{3}$, compared to other materials. SEM images of soil and biochars that were used for the quantification of porosity using PCAS software are presented in Figure 1. Soil had much lower porosity (25\%) compared to the biochars $(35-45 \%)$. The elemental carbon content of biochars $(70-84 \%$ d.w. $)$ were much higher than that of soil (4.7\% d.w.). Further information about the detailed physicochemical characterization of the biochars tested in this study is discussed elsewhere (Yargicoglu et al. 2015, Sadasivam and Reddy, 2015b). 


\subsection{Batch Adsorption Tests}

Batch adsorption tests conducted using soil and biochar-amended soils helped to determine the effects of $\mathrm{MC}$ and temperature on the $\mathrm{CH}_{4}$ adsorption kinetics and isotherm parameters. The linear form of the pseudo second-order kinetic model appeared to fit all of the adsorption data better with much higher $\mathrm{R}^{2}$ values that ranged from $0.95-0.99$, than the linear form of first-order kinetic model. Similar results were observed by Luo et al. (2011) that looked into the adsorption kinetics of methane onto activated carbon. Equilibrium conditions within all the batch adsorption test units in the current study were achieved at the end of two hours from the initiation of the tests. The equilibrium $\mathrm{CH}_{4}$ adsorption capacity at higher headspace $\mathrm{CH}_{4}$ concentrations was reached in all the tests, which indicated that the $\mathrm{CH}_{4}$ adsorption sites in the soil and biochar-amended soils were exhausted and the materials could no longer adsorb further $\mathrm{CH}_{4}$ despite any increase in the levels of the initial headspace $\mathrm{CH}_{4}$ concentration. The linear form of the Langmuir isotherm model best represented the mechanisms of methane sorption in the cover materials tested.

The pseudo second-order kinetic model parameter $\left(\mathrm{q}_{\mathrm{e}}\right)$ that refers to the equilibrium $\mathrm{CH}_{4}$ adsorption capacity was compared for the soil and biochar-amended soils under dry, $25 \%$ and 75\% WHC (Sadasivam, 2015). Figure 2 shows typical $\mathrm{q}_{\mathrm{e}}$ results for soil and biochar-amended soils under dry conditions. The extent of $\mathrm{CH}_{4}$ adsorption onto biochar-amended soils was at least an order of magnitude higher than that of the cover soil alone. The presence of moisture in the cover materials resulted in a significant $(\alpha=0.05)$ decrease in the equilibrium adsorption capacity for all four types of biochar-amended soils, no matter what the amendment percentages. 
The equilibrium $\mathrm{CH}_{4}$ adsorption capacity for soil and biochar-amended soils increased with an increase in the levels of the initial $\mathrm{CH}_{4}$ concentrations, within the concentration range of this study (2 to15\% $\mathrm{CH}_{4} \mathrm{v} / \mathrm{v}$ ) regardless of the presence of moisture within the system. The equilibrium adsorption capacity under various moisture levels for the CE-WP1 amended soils was the highest, followed closely by the CE-WP2 and CE-AWP amended soils, while the least capacity was exhibited by the CE-WC amended soils.

The second-order kinetic rate $\left(\mathrm{k}_{2}\right)$ of $\mathrm{CH}_{4}$ adsorption in soil and biochar-amended soils is quantified under different moisture conditions (dry, 25\%WHC and 75\% WHC) (Sadasivam, 2015). Figure 3 shows typical $k_{2}$ results for soil and biochar-amended soils under dry conditions. The kinetic rate of $\mathrm{CH}_{4}$ adsorption in soil and biochar-amended soil decreased as the amount of moisture in the cover materials increased under all levels of initial headspace $\mathrm{CH}_{4}$ concentrations $(\% \mathrm{v} / \mathrm{v})$

Adsorption isotherm modeling was performed to determine the mechanisms that control the exchange of $\mathrm{CH}_{4}$ molecules between the adsorbent and the gas phase adsorbate, i.e. synthetic LFG mixture containing 50\% $\mathrm{CH}_{4}(\mathrm{v} / \mathrm{v})$. Both Langmuir and Freundlich isotherm models were investigated and the isotherm modeling parameters are presented in Sadasivam (2015). The $\mathrm{R}^{2}$ values fit for all the tests ranged from $0.97-0.99$. The maximum $\mathrm{CH}_{4}$ adsorption capacity onto soil and biochar-amended soils was found to decrease significantly $(\alpha=0.05)$ with the increase in the moisture content, irrespective of the type of biochar amended (Figure 4). Under dry conditions, the maximum $\mathrm{CH}_{4}$ adsorption capacity was the highest for all CE-WP1 amended soils, in the range of $0.015-0.085 \mathrm{~mol} / \mathrm{kg}$, followed closely by all CE-WP2 amended biochars, in the range from $0.014-0.080 \mathrm{~mol} / \mathrm{kg}$ at various amendment ratios tested. Soils amended with CE-WC biochar exhibited the capacity for $\mathrm{CH}_{4}$ adsorption, which ranged between $0.010-0.047$ 
$\mathrm{mol} / \mathrm{kg}$ under as-is conditions. Overall, the $\mathrm{CH}_{4}$ adsorption capacity of all biochar-amended soils was an order of magnitude higher, ranging between $0.010-0.085 \mathrm{~mol} / \mathrm{kg}$, as compared to that of the cover soil, which had a sorption capacity of $0.0019 \mathrm{~mol} / \mathrm{kg}$.

The second-order kinetic model parameter $\left(\mathrm{q}_{\mathrm{e}}\right)$ that corresponds to the equilibrium $\mathrm{CH}_{4}$ adsorption capacity of soil and biochar-amended soils at room temperature $\left(25^{\circ} \mathrm{C}\right), 35^{\circ} \mathrm{C}$ and $45^{0} \mathrm{C}$, are presented in Sadasivam (2015). Figure 2 shows the typical results at room temperature. The equilibrium adsorption capacity values for all biochar-amended soils dropped as the temperature rose, while that of soil rose with the increase in temperature, under the test conditions specific to this study. The kinetic rate of $\mathrm{CH}_{4}$ adsorption, $\mathrm{k}_{2}\left(\mathrm{~kg} \cdot \mathrm{mol}^{-1} \mathrm{~min}^{-1}\right)$ onto soil and biochar-amended soils at $25^{\circ} \mathrm{C}, 35^{\circ} \mathrm{C}$ and $45^{\circ} \mathrm{C}$, is presented in Sadasivam (2015) and Figure 3 shows typical results at room temperature. Rate of methane sorption was found to decrease with the increase in temperature for all of the materials tested. The Langmuir and Freundlich isotherm model parameters for soil and biochar-amended soils under room temperature $\left(25^{\circ} \mathrm{C}\right)$, $35^{\circ} \mathrm{C}$ and $45^{\circ} \mathrm{C}$ are presented in Sadasivam (2015). The Langmuir model produced the best fit for the adsorption data for all the materials with higher $\mathrm{R}^{2}$ values $(0.97-0.99)$ as compared the Freundlich model. The maximum $\mathrm{CH}_{4}$ adsorption capacity for soil and biochar-amended soils at different temperature is shown in Figure 4. The maximum adsorption capacity for soil increased as the temperature increased, while that of all biochar-amended soils decreased with the increase in temperature. The CE-WP1 amended soils exhibited the highest levels of $\mathrm{CH}_{4}$ adsorption capacity and the order of adsorption capacity for other materials showed trends similar to the results presented for $\mathrm{CE}-\mathrm{WC}$ amended soils having the least $\mathrm{CH}_{4}$ adsorption capacity.

\subsection{Column Adsorption Tests}


The effects of $\mathrm{CH}_{4}$ inflow rates and moisture on the $\mathrm{CH}_{4}$ adsorption capacity for soil and biochar-amended soils are presented in Sadasivam (2015). $\mathrm{The}^{\mathrm{CH}_{4}}$ adsorption capacity for soil was lower than all of the biochar-amended soils irrespective of the moisture levels within the packed columns. Increase in adsorption capacity was consistent with an increase in the percentage of biochar-amendment. The presence of moisture within the materials appeared to reduce the $\mathrm{CH}_{4}$ adsorption capacity for all cover materials. However, the changes in $\mathrm{CH}_{4}$ adsorption capacity were not statistically significant $(\alpha=0.05)$ between dry and $25 \%$ WHC conditions, while the reduction was significant $(\alpha=0.05)$ between dry and 75\% WHC conditions for soil and biochar-amended soils. The $\mathrm{CH}_{4}$ adsorption capacity was higher for all materials under low flow-rates $(3-5 \mathrm{ml} / \mathrm{min})$ as compared to higher flow rate corresponding to 7.3 $\mathrm{ml} / \mathrm{min}$. Overall, with respect to the order of adsorption capacity for the biochar-amended materials, the column test results agree with the batch adsorption test results. This means that the CE-WP1 amended soils had the highest capacity followed by CE-WP2 amended soils, and the $\mathrm{CE}-\mathrm{WC}$ amended soils had the least $\mathrm{CH}_{4}$ adsorption capacity.

\subsection{Column Adsorption and Transport Modeling}

Predictive transport modeling was performed to determine the $\mathrm{CH}_{4}$ dispersion coefficients by using the 1-D advection dispersion equation given by Eq (9). The experimental breakthrough curves obtained for soil and the biochar-amended soils under different moisture conditions were fitted by changing the dispersion coefficient values from knowing all the other parameters in the transport equation. Typical experimental and model breakthrough curves for 
soil under different moisture levels are shown in Figure 5. The various parameters used for transport modeling for the soil and biochar-amended soils under different moisture conditions are listed in Table 3. The dispersion coefficients for soil ranged between $4.3 \times 10^{-3}-4.5 \times 10^{-3} \mathrm{~m}^{2} \mathrm{~min}^{-}$

1. The dispersion coefficients for biochar-amended soils were one to two orders of magnitude higher than that of soil and ranged between $2.7 \times 10^{-2}-1.4 \times 10^{-1} \mathrm{~m}^{2} \mathrm{~min}^{-1}$. The goodness of fit $\left(\mathrm{R}^{2}\right)$ values for the transport modeling ranged between $0.96-0.99$. The $\mathrm{CH}_{4}$ dispersion coefficients were found to increase with an increase in the biochar-amendment percentages and to decrease with increase in moisture levels (Figure 4). The retardation factors for cover materials under dry conditions were much higher compared to those values under moist conditions (Table 2). Retardation factors quantified in this study are indicative of the ability of soil and biochar-amended soils to adsorb and retain $\mathrm{CH}_{4}$ within the cover system prior to breakthrough and is indicative of the retention time. Higher retardation factors imply that a longer time is required to achieve breakthrough the cover system.

\section{Discussion}

\subsection{Physicochemical characteristics}

The adsorption, dispersion and transport of methane through biochar-based landfill covers, availability of oxygen and water for the microbial methane oxidation and prevailing environment for methanotrophic activity can be significantly impacted by the physical and chemical characteristics of the cover materials. Optimal methanotrophic activity occurs under neutral to slightly basic soil conditions (Scheutz and Kjeldsen, 2004), and the cover materials tested in this study had neutral to slightly basic $\mathrm{pH}$. In general, methanotrophic activity in soils is 
fairly resistant to significant $\mathrm{pH}$ gradients. Thus, the $\mathrm{pH}$ of cover materials tested in this study appear to favor the methanotrophic activity and promote methane oxidation when used as a biocover in landfills. It is critical to account for the effects of moisture since water in biochar pores can increase the habitability of biochar to microbial activities (Lehmann and Joseph, 2009). However, the high moisture content may also slow down the gaseous transport processes in the soil since molecular diffusion in water is many times slower than in air (Cabral and Jugnia, 2010).

The organic content of biochar-amended soils is much higher than that of soil, which indicates a significant increase in the organic fraction of cover materials with an increase in the biochar amendments. The organic matter fraction of all the sterilized CE-biochars ranged from $82-97 \%$ (Sadasivam and Reddy, 2015a). Though the biochar-soil mixtures exhibited much lower organic content compared to that of the biochars alone, there was a significant increase in the organic matter fraction compared to that of soil alone. The organic contents reported here, for the sterilized samples, are representative of all the available carbon content (fixed or volatile) that can burn off in the muffle furnace temperature ranging from $450-550^{\circ} \mathrm{C}$. In general, the adsorption capacity of soils can be increased with an increase in the amounts of organic soil fraction. As the amount of organic matter in any particular soil increases, the available surface area for adsorption increases (Lehmann and Joseph, 2009); this, in turn, results in better adsorption capacity for that soil. The characterization of all materials for their respective organic contents is critical to this study since previous studies showed that the extent of microbial methane oxidation can be increased by adding organic rich amendments to landfill cover soils (Stern et al. 2007; Huber-Humer et al. 2008; Huber-Humer et al. 2009; Pederson et al. 2011). 
The particle size of the cover materials can significantly affect the extent of adsorption by altering the available surface area of the adsorbent and can serve as a controlling factor in the transport of gases through the cover layers (Sadasivam and Reddy, 2015b). Organic cover soil amendments with greater particle sizes can adversely affect the landfill performance in the longterm by allowing higher infiltration of rainwater, resulting in excessive leachate generation. This means that it is critical to limit the percolation of water through cover systems and imperative to meet the site-specific design standards with respect to hydraulic conductivity. The CE-WC biochar had the largest average particle size since the feedstock was comprised of wood chips with visibly large, chunky pieces of charred wood. The finer ash fraction in CE-WP1 biochar resulted in much smaller average particle sizes for all CE-WP1-amended soils compared to the other biochar-amended soils.

The water holding capacity (WHC) values correspond to the maximum amount of water that a known mass of the adsorbent can hold when excessive quantities of water are passed through it. From a practical point of view, this test can be used to determine the amount of water retained within the pores of the cover materials during a rain event. The addition of biochars to the soil increased the water retention capacity of soil and this can favor the growth and activity of MOB as it limits the potential for water-stressed conditions to occur within the cover system.

The porosity of biochar-amended soils increased significantly with the increase in the percentage of biochar amendment. The SEM images for soil and biochars are shown in Figure 1. Image analysis results clearly show that the biochars are highly porous materials with greater inter-particle and intra-particle porosity as compared to that of soil, thereby enhancing the porosity of soil with an increase in the level of amendment. The elemental carbon content of the biochars was much higher than that of the soil mainly due to the pyrogenic production conditions 
and the feedstock of the biochars. Thus, amending the soil with carbon-rich biochars can result in a subsequent rise in the carbon content of the cover material, thereby facilitating enhanced $\mathrm{CH}_{4}$ adsorption, diffusion and oxidation within the biochar-based cover system.

\subsection{Effect of moisture on $\mathrm{CH}_{4}$ adsorption}

The kinetic data for $\mathrm{CH}_{4}$ adsorption onto soil and biochar-amended soils under different levels of moisture, temperature and initial $\mathrm{CH}_{4}$ headspace concentrations were best represented by Lagergren's second-order kinetic model. Similar observations were reported in a recent study that investigated the adsorption kinetics of methane onto activated carbon (Luo et al. 2011). The pseudo second-order kinetic model parameters are used to determine the extent of molecular exchange at the interface between the adsorbate in the gas phase and the adsorbent. From the adsorption kinetic data, it is evident that the amount of methane adsorbed onto the materials at equilibrium increases with increasing initial headspace $\mathrm{CH}_{4}$ concentrations irrespective of the level of MC and temperature. This could be attributed to the increase in the amount of methane molecules readily available for adsorption onto soil and biochar-amended soil surfaces at higher headspace concentrations, as it promotes elevated amounts of $\mathrm{CH}_{4}$ adsorbed at equilibrium.

Several studies examined the effects of moisture content on the adsorption of methane onto coals (Levy et al. 1997; Bustin et al. 1998) and activated carbon (Zhou et al. 2001; Farzad et al. 2007). From these studies, it is evident that the presence of moisture reduces the amount of methane adsorbed onto pyrogenic substances within the temperature and pressure ranges used in this study. The inhibition of the extent of $\mathrm{CH}_{4}$ adsorption at equilibrium onto soil and biocharamended soils with an increase in the MC is in accordance with the second-order kinetic model 
assumption that the extent of adsorption depends on only the available surface sites that are affected by the presence of moisture in the adsorbents (Liu, 2008). Moreover, a water molecule has a diameter of $0.306 \mathrm{~nm}$ as compared to a methane molecule, with a diameter of $0.38 \mathrm{~nm}$, which makes it harder for methane to penetrate the surface pores in the presence of moisture (Zhou et al. 2001), thus lowering the values of both $\mathrm{q}_{\mathrm{e}}$ and $\mathrm{k}_{2}$ in the presence of moisture as opposed to those values observed under dry conditions. Biochar-amended soils exhibited a greater inhibition in the rate at which $\mathrm{CH}_{4}$ was adsorbed than soil. This higher reduction in the extent of $\mathrm{CH}_{4}$ adsorption can be attributed to greater competition between the $\mathrm{CH}_{4}$ and $\mathrm{H}_{2} \mathrm{O}$ molecules in the case of pyrogenic substances.

The maximum $\mathrm{CH}_{4}$ adsorption capacity of CE-WP1-amended soils was consistently higher for all amendment ratios under dry conditions (Figure 4). CE-WP1 exhibited greater porosity of $44.4 \%$ than soil $(25 \%)$. The adsorption capacity of CE-WC amended soils was the least as they also exhibited the least porosity among the biochars. The maximum adsorption capacity for only the biochars tested showed a similar order with respect to the biochar types, and more detailed information on this is presented elsewhere (Sadasivam and Reddy 2015a). Typically, the sorption of methane onto carbon surfaces was hydrophobic which implies that the adsorbate $\left(\mathrm{CH}_{4}\right)$-adsorbent interactions and bonding are strong and are not affected by the presence of water molecules. On the other hand, the presence of oxygenated active sites on carbon surfaces result in more of a hydrophilic behavior wherein, the presence of water molecules significantly hinders the extent of adsorbate $\left(\mathrm{CH}_{4}\right)$ - adsorbent bonding resulting in higher amounts of sorption sites being occupied by water (Müller and Gubbins, 1998).

\subsection{Effect of temperature of $\mathrm{CH}_{4}$ adsorption}


Reduction in the kinetic rate of $\mathrm{CH}_{4}$ adsorption at higher temperatures for soil and all biochar-amended soils can be attributed to the decrease in micropore width on the adsorbent's surface as a result of increases in temperature, thus restricting the entry of methane molecules by assuming a simple linear pore filling model (Sakurovs et al. 2008). To evaluate the reason behind the increasing and decreasing trends in $\mathrm{CH}_{4}$ adsorption capacity with the increase in temperatures, the Clausius-Clapeyron plot was used to obtain the heat of adsorption for the materials. The relationship between the equilibrium pressure of the adsorbate and the temperature of the adsorption medium is thermodynamically represented by the ClausiusClapeyron plot to evaluate the nature of adsorption process (McLaughlin et al. 1998; Vasanth Kumar et al. 2011; Ning et al. 2012). The Clausius-Clapeyron equation is represented as shown in Eqn. (10).

$$
-\frac{Q_{s t}}{R}=\left(\frac{d \ln p}{d(1 / T)}\right)
$$

Where $\mathrm{Q}_{\mathrm{st}}$ is the isosteric heat of adsorption $(\mathrm{kJ} / \mathrm{mol})$; $\mathrm{p}$ is the equilibrium pressure of adsorption, $(\mathrm{kPa}) ; \mathrm{T}$ is the temperature $(\mathrm{K})$; and $\mathrm{R}$ is the universal gas constant.

The slope of the plot of $\operatorname{lnC}$ versus $1 / \mathrm{T}$ in $\mathrm{Eq}(10)$ gives the value for isosteric heat of adsorption. The isosteric heat of adsorption values for soils and biochar-amended soils are presented in Table 3. The adsorption of methane onto soil was found to be endothermic (-30 to $118 \mathrm{~kJ} / \mathrm{mol}$ ) as a result of which the adsorption capacity was shown to increase with an increase in temperature. The positive heat of adsorption values for biochar-amended soils were indicative of exothermic reactions that resulted in a decrease in the adsorption capacity as the temperature increased. Several studies have found that the adsorption of methane onto pyrogenic substances 
has a positive heat of adsorption, which, in turn, implies that the adsorption process is exothermic in nature (Ning et al. 2012; Bagheri et al. 2011; Jagiello et al. 1995). It is to be noted that the temperatures within a landfill cover under field conditions is expected to vary widely and can also drop to sub-zero levels depending upon the climatic conditions. However, the results from this study can be used to understand the overall trends in the sorption capacity of biocharbased cover soils with temperatures around the optimal values previously reported for the process of methane oxidation to occur (Spokas and Bogner, 2011).

The range in heat of adsorption values for all biochar-amended soils increased with the increase in the biochar amendment. The addition of biochars to soil changes the nature of $\mathrm{CH}_{4}$ adsorption process from endothermic to exothermic, a change in the enthalpy of the $\mathrm{CH}_{4}$ adsorption that could be attributed to the changes in the oxidation-reduction potential of soil brought about by the biochar amendments. The oxidation reduction potential (ORP) values for biochar-amended soils indicate that they appear to be under more reduced conditions as compared to that of soil and that the ORP values become more negative with the increase in the biochar-amendment. This could explain the possible increase in the enthalpy of adsorption with increasing biochar-amendment. Similar trends in the enthalpy of $\mathrm{CH}_{4}$ adsorption were observed by Rychilki and Terzyk (1995). The presence of a potential energy barrier in the case of materials under slightly more oxidized conditions restricted the entry of $\mathrm{CH}_{4}$ as the smallest of the pores were blocked by surface functionalities (Rychilki and Terzyk, 1995). The presence of such physical barrier on the soil surface could be possible since the ORP value of soil was less negative as compared to that of biochar-amended soils, which may have resulted in an endothermic effect to the overall adsorption enthalpy. The packing and the placement of methane molecules within the porous structure of biochars is largely dependent upon the pore size 
distribution and the presence of activated surfaces. The majority of biochar porosity was found to be contributed by the micropores $(<2 \mathrm{~nm}$ size) and the extent of methane adsorption onto microporous materials were found to be much stronger compared to meso- and/or macropores (Sadasivam and Reddy, 2015b).

\subsection{Coupled adsorption, dispersion and transport}

The $\mathrm{CH}_{4}$ adsorption capacity appeared to be higher at low flow rates since the residence time for inlet $\mathrm{CH}_{4}$ gas is higher at low inflow rates, resulting in a better contact between the adsorbate molecules and adsorbent surfaces over a longer duration of time. The $\mathrm{CH}_{4}$ adsorption capacity was the highest in the case of the CE-WP1 amended soils, followed closely by the CEWP2 amended soils, while the lowest adsorption capacity was exhibited by CE-WC amended soils. This trend in the adsorption capacity of materials to concur with that of the batch test results. The presence of moisture within the columns appears to impede the $\mathrm{CH}_{4}$ adsorption onto material surfaces regardless of the biochar-types and biochar amendment percentages to soil. These observations also agree with the batch adsorption test results.

The $\mathrm{CH}_{4}$ dispersion coefficient values for soil, based on previous studies for different gas mixes ranged between $1.794 \times 10^{-5}-2.047 \times 10^{-5} \mathrm{~m}^{2}$ gas/s (Scheutz et al. 2009). In this study, the $\mathrm{CH}_{4}$ dispersion coefficients appeared to be slightly higher (between $7.167 \times 10^{-5}-7.5 \times 10^{-5} \mathrm{~m}^{2}$ gas/s). This could be due to the possible differences in the physical properties of the soils such as porosity. In general, the dispersion coefficients decreased slightly with increases in the level of moisture within the columns (Table 2) and could be due to the impedance in the movement of $\mathrm{CH}_{4}$ through moist cover materials caused by the presence of water molecules. The presence of 
water in carbonaceous materials was found to reduce the gas diffusivity through the pores since water acts as a swelling agent. However, the permeability of $\mathrm{CH}_{4}$ in water is very low, in the order of $10^{-5} \mathrm{~cm}^{2} / \mathrm{s}$ (Busch et al. 2004), which implies that the presence of moisture is not a major contributor to the hindrance of gas diffusion process because there is only a very slight, statistically insignificant decrease in the diffusion coefficients of the soil and biochar-amended soils with the increase in moisture levels.

Amendment of biochars to soil significantly $(\alpha=0.05)$ increased the $\mathrm{CH}_{4}$ dispersion, which could be due to the rapid transport of $\mathrm{CH}_{4}$ within the highly porous structures of biocharamended soils. The transport $\mathrm{CH}_{4}$ through highly microporous carbon structures increased by 3-4 orders of magnitude as compared to its transport through zeolites and crystalline structures (Skoulidas et al. 2002). There was an increasing trend $\left(\mathrm{R}^{2}=0.77\right)$ in the dispersion of $\mathrm{CH}_{4}$ through cover materials as porosity increased (Table 2). Similarly, the diffusivity of oxygen within soil covers increased with the increasing porosity of the material (Aachib et al. 2004). The porosity of biochar-amended soils were positively correlated with the $\mathrm{CH}_{4}$ dispersion coefficients (Figure 6). Overall, the transport of $\mathrm{CH}_{4}$ through cover soil was enhanced by the addition of biochars, thereby increasing the diffusivity and allowing for higher rates of gas transport through the biochar-amended soils.

\section{Conclusions}

In this study, the $\mathrm{CH}_{4}$ adsorption and transport properties of landfill cover soil and four different types of biochar-amended landfill cover soils were investigated and compared at different levels of moisture, temperature and biochar amendment. The physicochemical 
properties of the cover materials were characterized and were found to strongly influence the $\mathrm{CH}_{4}$ adsorption and transport properties. Based on the results obtained from this study, the following conclusions can be derived:

- The kinetic and equilibrium sorption data for soil and biochar-amended soils were represented by the pseudo second-order kinetic model and linear form of Langmuir isotherm model, respectively.

- A significant decrease in the $\mathrm{CH}_{4}$ adsorption capacity of soil and biochar-amended soils was found with an increase in the level of moisture.

- The maximum adsorption capacity for soil increased with an increase in temperature, while the opposite trend was observed in biochar-amended soils, which is attributed to the enthalpy of adsorption that was endothermic in the case of soil and exothermic in the case of biochar-amended soil.

- The extent of $\mathrm{CH}_{4}$ transport through soil (by accounting for adsorption) was two orders of magnitude lower $\left(7.5 \times 10^{-5} \mathrm{~m}^{2} / \mathrm{s}\right)$ compared to all biochar-amended soils $\left(1 \times 10^{-3}-2.5 \mathrm{x}\right.$ $\left.10^{-3} \mathrm{~m}^{2} / \mathrm{s}\right)$.

- The amendment of even a small quantity of biochar ( $2 \%$ by weight) to soil dramatically increased the $\mathrm{CH}_{4}$ transport and adsorption within the cover material by at least one order of magnitude implying the significant impact of the addition of biochars to the soil.

- The physicochemical properties of biochar considerably impacted the $\mathrm{CH}_{4}$ adsorption and transport properties of biochar-amended soil cover, implying the importance of prescreening biochars prior to their use for field applications.

The overall implications of this study indicate that amending cover soil with certain types of biochars can be a promising approach to promote the enhanced $\mathrm{CH}_{4}$ adsorption and gas 
transport within the cover system, thereby resulting in better environment for potentially higher rates of methane oxidation.

\section{Acknowledgement}

This research project is funded by the U.S. National Science Foundation (Grant CMMI $\# 1200799$ ), which is gratefully acknowledged. The content of this paper is a part of the doctoral thesis of the first author.

\section{References}

Aachib, M., Mbonimpa, M., and Aubertin, M. (2004). Measurement and prediction of the oxygen diffusion coefficient in unsaturated media, with applications to soil covers. Water Air Soil Poll. 156, 163-193.

Bagheri, N. and Albedi, J. (2011). Adsorption of methane on corn cobs based activated carbon. Chem. Eng. Res. Des. 89, 2038-2043.

Baring, H., Bucheli, T.D., Broman, D., and Gustafsson, O. (2002). Soot-water distribution coefficients for polychlorinated dibenzo-p-dioxins, polychlorinated dibenzofurans and polybrominated diphenylethers determined with the soot consolvency-column method. Chemosphere 49, 515-523.

Billemont, P., Coasne, B. and Weireld, G.D. (2013). Adsorption of Carbon Dioxide, Methane, and Their Mixtures in Porous Carbons: Effect of Surface Chemistry, Water Content, and Pore Disorder. Langmuir, 29, 3328- 3338. 
Boateng, A.A. (2007). Characterization and thermal conversion of charcoal derived from fluidized-bed fast pyrolysis oil production of switchgrass. Ind. Eng. Chem. Res., 46, $8857-8862$.

Borjesson, G., Sundh, I., and Svensson, B. (2004). Microbial oxidation of CH4 at different temperatures in landfill cover soils. FEMS Microbiol. Ecol. 48, 305-312.

Brown, R.A., Kercher, A.K., Nguyen, T.H., Nagle, D.C. and Ball, W.P. (2006). Production and characterization of synthetic wood chars for use as surrogates for natural sorbents. Org. Geochem. 37, 321-333.

Busch, A., Gensterblum, Y., Krooss, B.M. and Littke, R. (2004). Methane and carbon dioxide adsorption-diffusion experiments on coal: upscaling and modeling. Int. J Coal Geol. 60, $151-168$.

Bustin, R.M. and Clarkson, C.R. (1998). Geological controls on coalbed methane reservoir capacity and gas content. Int. J Coal Geol. 38, 3- 26.

Cavenati, S., Grande, C.A. and Rodrigues, A.E. (2005). Upgrade of Methane from Landfill Gas by Pressure Swing Adsorption. Energ. Fuel. 19, 2545-2555.

Chan, A.S.K. and Parkin, T.B. (2000). Evaluation of potential inhibitors of methanogenesis and methane oxidation in a landfill cover soil. Soil Biol. Biochem. 32, 158-1590.

Chan, K.Y., Van Zweiten, L., Meszaros, I., Downie, A. and Joseph, S. (2007). Agronomica values of greenwaste biochar as a soil amendment. Aust. J Soil Res. 45, 629-634.

Chanton, J., Abichou, T., Langford, C., Spokas, K., Hater, G., Green, R., et al. (2011). Observations on the methane oxidation capacity of landfill soils. Waste Manage. 31, 914925. 
Chathoth, S.M., He, L., Mamontov, E. and Melnichenko Y.B. (2012). Effect of carbon dioxide and nitrogen on the diffusivity of methane confined in nano-porous carbon aerogel. Micropor. Mesopor. Mat. 148, 101-106.

Chun, Y., Sheng, G. Y., Chiou, C. T., and Xing, B. S. (2004). Compositions and sorptive properties of crop residue-derived chars. Environ. Sci. Technol. 38, 4649-4655.

Dalal, R.C., Allen, D.E., Livesly, S.J. and Richards, G. (2008). Magnitude and biophysical regulators of methane emissions and consumption in the Australian agricultural, forest, and submerged landscapes: A review. Plant Soil 309, 43-76.

Farzad, S., Taghikhani, V., Ghotbi, C., Aminshahidi, B. and Lay, E.N. (2007). Experimental and Theoretical Study of the Effect of Moisture on Methane Adsorption and Desorption by Activated Carbon at 273.5 K. J Nat. Gas Chem. 16, 22- 30.

Fetter, C.W. (1999). Contaminant Hydrogeology. Second edition.

Foo, K.Y., and Hameed, B.H. (2010). Insights into the modeling of adsorption isotherm systems. Chem. Eng. J. 156, 2-10.

Gruszkiewicz, M.S., Naney, M.T., Blencoe, J.G., Cole, D.R., Pashin, J.C. and Carroll, R.E. (2009). Adsorption kinetics of $\mathrm{CO} 2, \mathrm{CH} 4$, and their equimolar mixture on coal from the Black Warrior Basin, West-Central Alabama. Int. J Coal Geol. 77, 23-33.

Huang, W., Peng, P., Yu, Z. and Fu, J. (2003). Effects of organic matter heterogeneity on sorption and desorption of organic contaminants by soils and sediments. Appl. Geochem. $18,955-972$.

Huber-Humer, M., Gebert, J., and Hilger, H. (2008). Biotic Systems to Mitigate Landfill Methane Emissions. Waste Manag. Res. 26, 33-46. 
Huber-Humer, M., Roder, S., and Lechner, P. (2009). Approaches to Assess Biocover Performance on Landfills. Waste Manage. 29, 2092-2104.

Huber-Humer, M., Tintner, J., and Lechner, K. B. (2011). Scrutinizing compost properties and their impact on methane oxidation efficiency. Waste Manage. 31, 871-883.

IPCC, 2013. Summary for Policymakers. In: Climate Change 2013: The Physical Science Basis. Contribution of Working Group I to the Fifth Assessment Report of the Intergovernmental Panel on Climate Change, Cambridge University Press, Cambridge, UK.

Lehmann, J. (2007). Bio-energy in the black. Front. Ecol. Environ. 5, 381-387.

Lehmann, J., Joseph, S. Biochar for Environmental Management: Science and Technology, 2009, Earthscan Publishing Co., London, UK

Levy, J.H., Day, S.J. and Killingley, J.S. (1997). Methane capacities of Bowen Basin coals related to coal properties. Fuel, 76, 813-819.

Liu, Y. (2008). New insights into pseudo-second order kinetic equation for adsorption. Colloids and Surfaces A: Physicochem. Eng. Aspects, 320, 275-278

Liu, C., Shi, B., Zhou, J., Tang, C. (2011). Quantification and characterization of microporosity by image processing, geometric measurement and statistical methods: application on SEM images of clay materials. Appl. Clay Sci. 54, 97-106.

Lou, Z., Wang, L., and Zhao, Y. (2011). Consuming un-captured methane from landfill using aged refuse bio-cover. Bioresource Technol. 102, 2328-2332

Lua, A.C., Yang, T. and Guo, J. (2004). Effects of pyrolysis conditions on the properties of activated carbons prepared from pistachio-nut shells. J. Anal. Appl. Pyrol. 72, 279-287. 
Luo, J., Liu, Y., Jiang, C., Chu, W., Jie. W., and Xie, H. (2011). Experimental and Modeling Study of Methane Adsorption on Activated Carbon Derived from Anthracite. J. Chem. Eng. Data, 56, 4919-4926.

McLaughlin, C.P. and Magee, T.R.A. (1998). The Determination of Sorption Isotherm and the Isosteric Heats of Sorption for Potatoes. J. Food Eng. 35, 261-280.

Müller, E. A., \& Gubbins, K. E. (1998). Molecular simulation study of hydrophilic and hydrophobic behavior of activated carbon surfaces. Carbon 36, 1433-1438.

Nguyen, T.H., Sabbah, I. and Ball, W.P. (2004). Sorption nonlinearity for organic contaminants with diesel soot: Method development and isotherm interpretation. Environ. Sci. Technol. 38, 3595- 3603.

Ning, P., Li, F., Yi, H., Tang, X., Peng, J., Li, Y., He, D., and Deng, H. (2012). Adsorption equilibrium of methane and carbon dioxide on microwave-activated carbon. Sep. Purif. Technol. 98, 321-326.

Ogata, A. and Banks, R.B. (1961). A solution of the differential equation of longitudinal dispersion in porous media. U.S. Geological Survey Professional Paper 411-A .

Paris, O., Zollfrank, C. and Zickler, G.A. (2005). Decomposition and carbonization of wood biopolymers - a microstructural study of soft wood pyrolysis. Carbon, 43, 53-66.

Park, S. Y., Brown, K. W., and Thomas, J. C. (2004). The use of biofilters to reduce atmosphericmethane emissions from landfills: Part I. biofilter design. Water Air Soil Pollut. 155, 63-85.

Pedersen, G. B., Scheutz, C., and Kjeldsen, P. (2011). Availability and properties of materials for the Fakse Landfill biocover. Waste Manage. 31, 884-894. 
Powelson, D. K., Chanton, J., Abichou, T., and Morales, J. (2006). Methane oxidation in waterspreading and compost biofilters. Waste Manage. Res. 24, 528-536.

Reddy, K.R., Yargicoglu, E.N., Yue, D., Yaghoubi, P. (2014). Enhanced microbial methane oxidation in landfill cover soil amended with biochar. J. Geotech. Geoenviron. Eng., ASCE 140 (9), 04014047. http://dx.doi.org/10.1061/(ASCE)GT.1943-5606.0001148.

Roncato, C.D.L., and Cabral, A.R. (2012). Evaluation of Methane Oxidation Efficiency of Two Biocovers: Field and Laboratory Results. J. Environ. Eng-ASCE. 138, 164-173.

Sadasivam, B. Y. (2015). Biochar-Based Cover System for Landfill Methane Mitigation: Quantifying Adsorption, Transport \& Oxidation. Ph.D. thesis, University of Illinois at Chicago, Chicago, IL.

Sadasivam, B. Y., and Reddy, K. R. (2015a) Adsorption and Transport of $\mathrm{CH}_{4}$ in Biochars Derived from Waste Wood Waste Manage. (Submitted).

Sadasivam, B.Y., and Reddy, K.R. (2015b). Influence of physico-chemical properties of different biochars on landfill methane adsorption. IFCEE2015, San Antonio, TX, March 17-21, 2015.

Sadasivam, B.Y., and Reddy, K.R. (2014). Landfill methane oxidation in soil and bio-based cover systems. Rev. Environ. Sci. Biotechnol. 13, 79-107.

Sakurovs, R., Day, S., Weir, S., and Duffy, G. (2008). Temperature dependence of sorption of gases by coals and charcoals. Int, J. Coal Geol. 73, 250-258.

Scheutz, C., Kjeldsen, P., Bogner, J. E., Visscher, A. D., Gebert, J., Hilger, H. A., et al. (2009). Microbial methane oxidation processes and technologies for mitigation of landfill gas emissions. Waste Manage. 27, 409-455. 
Scheutz, C., Mosbæk, H., and Kjeldsen, P. (2004). Attenuation of Methane and Volatile Organic Compounds in Landfill Soil Covers. J. Environ. Qual. 33, 61-71.

Scheutz, C., Pedersen, G. B., Costa, G., and Kjeldsen, P. (2009). Biodegradation of Methane and Halocarbons in Simulated Landfill Biocover Systems Containing Compost Materials. J. Environ. Qual. 38, 1363-1371.

Scheutz, C., Pedicone, A., Pedersen, G. B., and Kjeldsen, P. (2011). Evaluation of respiration in compost landfill biocovers intended for methane oxidation. Waste Manage. 21, 895-902.

Schimmelpfennig, S., and Glaser, B. (2012). One Step Forward toward Characterization: Some Important Material Properties to Distinguish Biochars. J. Environ. Qual. 41, 1001-1013.

Skoulidas, A.I., Ackerman, D.M., Johnson, J.K. and Sholl, D.S. (2002). Rapid Transport of Gases in Carbon Nanotubes. Phys. Rev. Lett. 89, 1-4.

Spokas, K. A., and E.Bogner, J. (2011). Limits and dynamics of Ch4 oxidation on landfill cover soils. Waste Manage. 31, 823-832.

Spokas, K., Bogner, J., and Chanton, a. J. (2011). A process-based inventory model for landfill CH4 emissions inclusive of seasonal soil microclimate and $\mathrm{CH} 4$ oxidation. J. Geophys. Res. 116, G04017

Stern, J. C., Chanton, J., Abichou, T., Powelson, D., Yuan, L., Escoriza, S., et al. (2007). Use of a biologically active cover to reduce landfill methane emissions and enhance methane oxidation. Waste Manage. 27, 1248 - 1258.

Tate, K.R., Ross, D.J., Saggar, S., Hedley, C.B., Dando, J., Singh, B.K. and Lamb, S.J. (2007). Methane uptake in soils from pinius radiata plantations, a reverting shrubland and adjacent pastures: Effects of land-use change, and soil texture, water and mineral nitrogen. Soil Biol. Biochem. 39, 1437-1449. 
Vasanth Kumar, K, Monteiro de Castro, M.C., Martinez-Escandell, M., Molina-Sabio, M. and Rodriguez-Reinoso, F. (2011). Heat of adsorption and binding affinity for hydrogen on pitch-based activated carbons. Chem. Eng. J. 168, 972-978.

Werner, C., Kiese, R. and Butterbach-Bahl, K. (2007). Soil-atmosphere exchange of $\mathrm{N}_{2} \mathrm{O}, \mathrm{CH}_{4}$ and $\mathrm{CO}_{2}$ and controlling environmental factors for tropical rainforest sites in western Kenya. J. Geophys. Res. 112, 1-15.

Wilshusen, J., Hettiaratchi, J., Visscherb, A. D., and Saint-Fortc, R. (2004). Methane oxidation and formation of EPS in compost:effect of oxygen concentration. Environ. Pollut. 129, 305-314.

Yanai, Y., Toyota, K. and Okazaki, M. (2007). Effects of charcoal addition on N2O emissions from soil resulting from rewetting air-dried soil in short-term laboratory experiments. Soil Sci. Plant Nutr. 53, 181-188.

Yang, Y. and Shen, G. (2003). Enhanced pesticide sorption by soils containing particulate matter from crop residue burns. Environ. Sci. technol. 37, 3635-3639.

Yargicoglu, E., Sadasivam, B.Y., Reddy, K.R., Spokas, K., (2015). Physical and chemical characterization of waste wood derived biochars. Waste Manage. 36, 256-268.

Zhang, T., Walawender, W.P., Fan, L.T., Fan, M., Daugaard, D. and Brown, R.C. (2004). Preparation of activated carbon from forest and agricultural residues through $\mathrm{CO} 2$ activation. Chem. Eng. J. 105, 53-59.

Zhou, L., Sun, Y. and Zhou, Y. (2002). Enhancement of the methane storage on activated carbon by preadsorbed water. AlChE J. 48, 2412 -2416. 
Table 1: Physical-Chemical Properties of Soil and Biochar-Amended Soils

\begin{tabular}{|c|c|c|c|c|c|c|c|c|c|c|}
\hline Material & $\mathbf{p H}$ & $\begin{array}{l}\text { ORP } \\
(\mathbf{m V})\end{array}$ & $\begin{array}{l}\text { MC } \\
(\%)\end{array}$ & $\begin{array}{l}\text { OC } \\
(\%)\end{array}$ & $\begin{array}{l}\text { Average } \\
\text { Particle } \\
\text { Size } \\
(\mathrm{mm}) \\
\end{array}$ & SG & $\begin{array}{l}\text { WHC } \\
(\%)\end{array}$ & $\begin{array}{l}\text { Dry } \\
\text { Density } \\
\left(\mathrm{g} / \mathrm{cm}^{3}\right)\end{array}$ & $\begin{array}{c}\text { Porosity } \\
(\%)\end{array}$ & $\begin{array}{c}\text { Elemental } \\
\text { Carbon } \\
(\%)\end{array}$ \\
\hline Soil (S) & 7.3 & -35.9 & 2.1 & 0.8 & 0.03 & 2.59 & 20.9 & 1.89 & 25 & 4.7 \\
\hline $\mathrm{S}+2 \% \mathrm{WP} 1$ & 7.4 & -43.4 & 0.55 & 2.14 & 0.10 & 2.53 & 34.99 & 1.69 & -- & -- \\
\hline $\mathrm{S}+5 \% \mathrm{WP} 1$ & 7.3 & -40.4 & 1.34 & 5.39 & 0.20 & 2.41 & 36.91 & 1.66 & -- & -- \\
\hline $\mathrm{S}+10 \% \mathrm{WP} 1$ & 7.3 & -39.1 & 0.00 & 14.50 & 0.24 & 2.24 & 37.10 & 1.49 & -- & -- \\
\hline CE-WP1 & 6.2 & 35.1 & 0.18 & 96.0 & 1.13 & 0.77 & 142.4 & 0.56 & 44.4 & 70.7 \\
\hline $\mathrm{S}+2 \% \mathrm{WP} 2$ & 7.5 & -45.5 & 0.00 & 1.65 & 0.20 & 2.51 & 21.00 & 1.54 & -- & -- \\
\hline $\mathrm{S}+5 \% \mathrm{WP} 2$ & 7.4 & -47.8 & 0.34 & 6.28 & 0.21 & 2.38 & 21.73 & 1.60 & -- & -- \\
\hline $\mathrm{S}+10 \% \mathrm{WP} 2$ & 7.4 & -48.5 & 0.62 & 12.45 & 0.22 & 2.33 & 22.13 & 1.66 & -- & -- \\
\hline CE-WP2 & 6.8 & 2.3 & 0.14 & 97.0 & 3.15 & 0.59 & 50.6 & 0.52 & 41.4 & 74.0 \\
\hline $\mathrm{S}+2 \%$ AWP & 7.5 & -43.7 & 0.56 & 2.81 & 0.22 & 2.55 & 27.23 & 1.65 & -- & -- \\
\hline $\mathrm{S}+5 \%$ AWP & 7.6 & -48.3 & 0.66 & 4.21 & 0.23 & 2.49 & 29.27 & 1.61 & -- & -- \\
\hline S+10\%AWP & 7.5 & -45.2 & 0.52 & 8.53 & 0.26 & 2.46 & 32.43 & 1.33 & -- & -- \\
\hline CE-AWP & 6.1 & -48.7 & 0.47 & 82.3 & 5.75 & 0.91 & 80.8 & 0.53 & 39.9 & 78.1 \\
\hline $\mathrm{S}+2 \% \mathrm{WC}$ & 7.0 & -47.8 & 0.89 & 2.04 & 0.34 & 2.50 & 34.10 & 1.61 & -- & -- \\
\hline $\mathrm{S}+5 \% \mathrm{WC}$ & 7.1 & -49.2 & 1.09 & 2.27 & 0.38 & 2.44 & 35.46 & 1.54 & -- & -- \\
\hline $\mathrm{S}+10 \% \mathrm{WC}$ & 7.2 & -52.4 & 0.69 & 2.41 & 0.43 & 2.33 & 36.52 & 1.24 & -- & -- \\
\hline CE-WC & 7.0 & -58.1 & 0.65 & 91.0 & 6.1 & 0.87 & 96.4 & 0.38 & 35.6 & 84.0 \\
\hline
\end{tabular}

$\mathrm{ORP}=$ oxidation-reduction potential; $\mathrm{MC}=$ moisture content; $\mathrm{OC}=$ organic content; $\mathrm{SG}=$ specific gravity; WHC=water holding capacity 
Table 2: Summary of Column Adsorption Modeling Parameters

\begin{tabular}{|c|c|c|c|c|c|c|}
\hline $\begin{array}{c}\text { Cover } \\
\text { Material }\end{array}$ & $\mathrm{D}\left(\mathrm{m}^{2} / \mathrm{min}\right)$ & $\begin{array}{c}K_{D} \\
\left(\mathrm{~m}^{3} / \mathrm{kg}\right)\end{array}$ & $\varepsilon(\%)$ & $\rho\left(\mathrm{kg} / \mathrm{m}^{3}\right)$ & $\mathbf{R}^{2}$ & $\begin{array}{c}\text { Retardation } \\
\text { Factor }\end{array}$ \\
\hline \multicolumn{7}{|c|}{ Dry Conditions } \\
\hline Soil (S) & 0.0045 & 0.0003 & 25 & 1890 & 0.99 & 3.3 \\
\hline $\mathrm{S}+2 \% \mathrm{WP} 2$ & 0.030 & 0.002 & 26 & 1540 & 0.99 & 12.8 \\
\hline $\mathrm{S}+5 \% \mathrm{WP} 2$ & 0.108 & 0.005 & 28 & 1600 & 0.99 & 29.6 \\
\hline $\mathrm{S}+10 \% \mathrm{WP} 2$ & 0.122 & 0.012 & 30 & 1660 & 0.99 & 67.4 \\
\hline $\mathrm{S}+2 \% \mathrm{WP} 1$ & 0.029 & 0.003 & 34 & 1690 & 0.99 & 15.9 \\
\hline $\mathrm{S}+5 \% \mathrm{WP} 1$ & 0.142 & 0.0107 & 35 & 1660 & 0.99 & 51.7 \\
\hline $\mathrm{S}+10 \% \mathrm{WP} 1$ & 0.148 & 0.012 & 36 & 1490 & 0.98 & 50.7 \\
\hline $\mathrm{S}+2 \% \mathrm{AWP}$ & 0.039 & 0.002 & 26 & 1650 & 0.99 & 13.7 \\
\hline $\mathrm{S}+5 \% \mathrm{AWP}$ & 0.076 & 0.0046 & 27 & 1610 & 0.99 & 28.4 \\
\hline S+10\%AWP & 0.085 & 0.0083 & 29 & 1330 & 0.99 & 39.1 \\
\hline $\mathrm{S}+2 \% \mathrm{WC}$ & 0.060 & 0.0017 & 27 & 1610 & 0.98 & 11.1 \\
\hline $\mathrm{S}+5 \% \mathrm{WC}$ & 0.095 & 0.0037 & 28 & 1540 & 0.99 & 21.4 \\
\hline $\mathrm{S}+10 \% \mathrm{WC}$ & 0.098 & 0.0068 & 29 & 1240 & 0.98 & 30.1 \\
\hline \multicolumn{7}{|c|}{$25 \% \mathrm{WHC}$} \\
\hline Soil (S) & 0.0044 & 0.0003 & 25 & 1890 & 0.99 & 3.2 \\
\hline $\mathrm{S}+2 \% \mathrm{WP} 2$ & 0.029 & 0.002 & 26 & 1540 & 0.99 & 12.8 \\
\hline $\mathrm{S}+5 \% \mathrm{WP} 2$ & 0.107 & 0.0047 & 28 & 1600 & 0.99 & 27.9 \\
\hline $\mathrm{S}+10 \% \mathrm{WP} 2$ & 0.119 & 0.0082 & 30 & 1660 & 0.96 & 46.4 \\
\hline $\mathrm{S}+2 \% \mathrm{WP} 1$ & 0.028 & 0.0026 & 34 & 1690 & 0.99 & 13.9 \\
\hline $\mathrm{S}+5 \% \mathrm{WP} 1$ & 0.110 & 0.0071 & 35 & 1660 & 0.98 & 34.7 \\
\hline $\mathrm{S}+10 \% \mathrm{WP} 1$ & 0.140 & 0.0105 & 36 & 1490 & 0.97 & 44.5 \\
\hline $\mathrm{S}+2 \% \mathrm{AWP}$ & 0.036 & 0.0017 & 26 & 1650 & 0.99 & 11.8 \\
\hline $\mathrm{S}+5 \% \mathrm{AWP}$ & 0.071 & 0.0041 & 27 & 1610 & 0.98 & 25.4 \\
\hline S+10\%AWP & 0.079 & 0.0064 & 29 & 1330 & 0.99 & 30.35 \\
\hline $\mathrm{S}+2 \% \mathrm{WC}$ & 0.058 & 0.0014 & 27 & 1610 & 0.98 & 9.3 \\
\hline $\mathrm{S}+5 \% \mathrm{WC}$ & 0.091 & 0.0032 & 28 & 1540 & 0.98 & 18.6 \\
\hline $\mathrm{S}+10 \% \mathrm{WC}$ & 0.095 & 0.006 & 29 & 1240 & 0.99 & 26.7 \\
\hline \multicolumn{7}{|c|}{$75 \% W H C$} \\
\hline Soil $(\mathrm{S})$ & 0.0043 & 0.0002 & 25 & 1890 & 0.99 & 2.5 \\
\hline $\mathrm{S}+2 \% \mathrm{WP} 2$ & 0.027 & 0.0014 & 26 & 1540 & 0.99 & 9.3 \\
\hline $\mathrm{S}+5 \% \mathrm{WP} 2$ & 0.106 & 0.0036 & 28 & 1600 & 0.99 & 21.6 \\
\hline $\mathrm{S}+10 \% \mathrm{WP} 2$ & 0.118 & 0.0061 & 30 & 1660 & 0.98 & 34.8 \\
\hline $\mathrm{S}+2 \% \mathrm{WP} 1$ & 0.027 & 0.0023 & 34 & 1690 & 0.99 & 12.4 \\
\hline $\mathrm{S}+5 \% \mathrm{WP} 1$ & 0.095 & 0.0030 & 35 & 1660 & 0.99 & 15.2 \\
\hline $\mathrm{S}+10 \% \mathrm{WP} 1$ & 0.110 & 0.008 & 37 & 1490 & 0.99 & 34.1 \\
\hline $\mathrm{S}+2 \% \mathrm{AWP}$ & 0.034 & 0.0014 & 26 & 1650 & 0.99 & 9.9 \\
\hline $\mathrm{S}+5 \% \mathrm{AWP}$ & 0.070 & 0.0032 & 27 & 1610 & 0.99 & 20.1 \\
\hline S+10\%AWP & 0.070 & 0.005 & 29 & 1330 & 0.98 & 23.9 \\
\hline $\mathrm{S}+2 \% \mathrm{WC}$ & 0.054 & 0.0013 & 27 & 1610 & 0.99 & 8.8 \\
\hline $\mathrm{S}+5 \% \mathrm{WC}$ & 0.088 & 0.0027 & 28 & 1540 & 0.99 & 15.9 \\
\hline $\mathrm{S}+10 \% \mathrm{WC}$ & 0.092 & 0.0038 & 29 & 1240 & 0.99 & 17.2 \\
\hline
\end{tabular}


Table 3: Heat of Adsorption for $\mathrm{CH}_{4}$ in Biochar-Amended Soils

\begin{tabular}{ll}
\hline Material Tested & Heat of Adsorption (kJ/mol) \\
\hline Soil (S) & -30 to -118 \\
S+2\%WP2 & $24-61$ \\
S+5\%WP2 & $42-256$ \\
S+10\%WP2 & $57-380$ \\
S+2\%WP1 & $38-248$ \\
S+5\%WP1 & $30-297$ \\
S+10\%WP1 & $50-440$ \\
S+2\%AWP & $30-240$ \\
S+5\%AWP & $34-402$ \\
S+10\%AWP & $125-400$ \\
S+2\%WC & $33-300$ \\
S+5\%WC & $39-290$ \\
S+10\%WC & 380 \\
\hline
\end{tabular}




\section{Figure Captions:}

Figure 1: SEM images of: (a) Soil; (b) CE-WP1; (c) CE-WP2; and (d) CE-AWP and (e) CWWC at magnification of 1000

Figure 2: Equilibrium $\mathrm{CH}_{4}$ adsorption capacity of soil and biochar amended soils under dry condition

Figure 3: Kinetic rate of $\mathrm{CH}_{4}$ adsorption in soil and biochar-amended soils under dry condition

Figure 4: Effect of moisture content and temperature on maximum $\mathrm{CH}_{4}$ adsorption capacity of soil and biochar-amended soils

Figure 5: Comparison of experimental and modeled breakthrough curves for soil

Figure 6: Correlation between $\mathrm{CH}_{4}$ dispersion coefficient and porosity of soil and biocharamended soils 

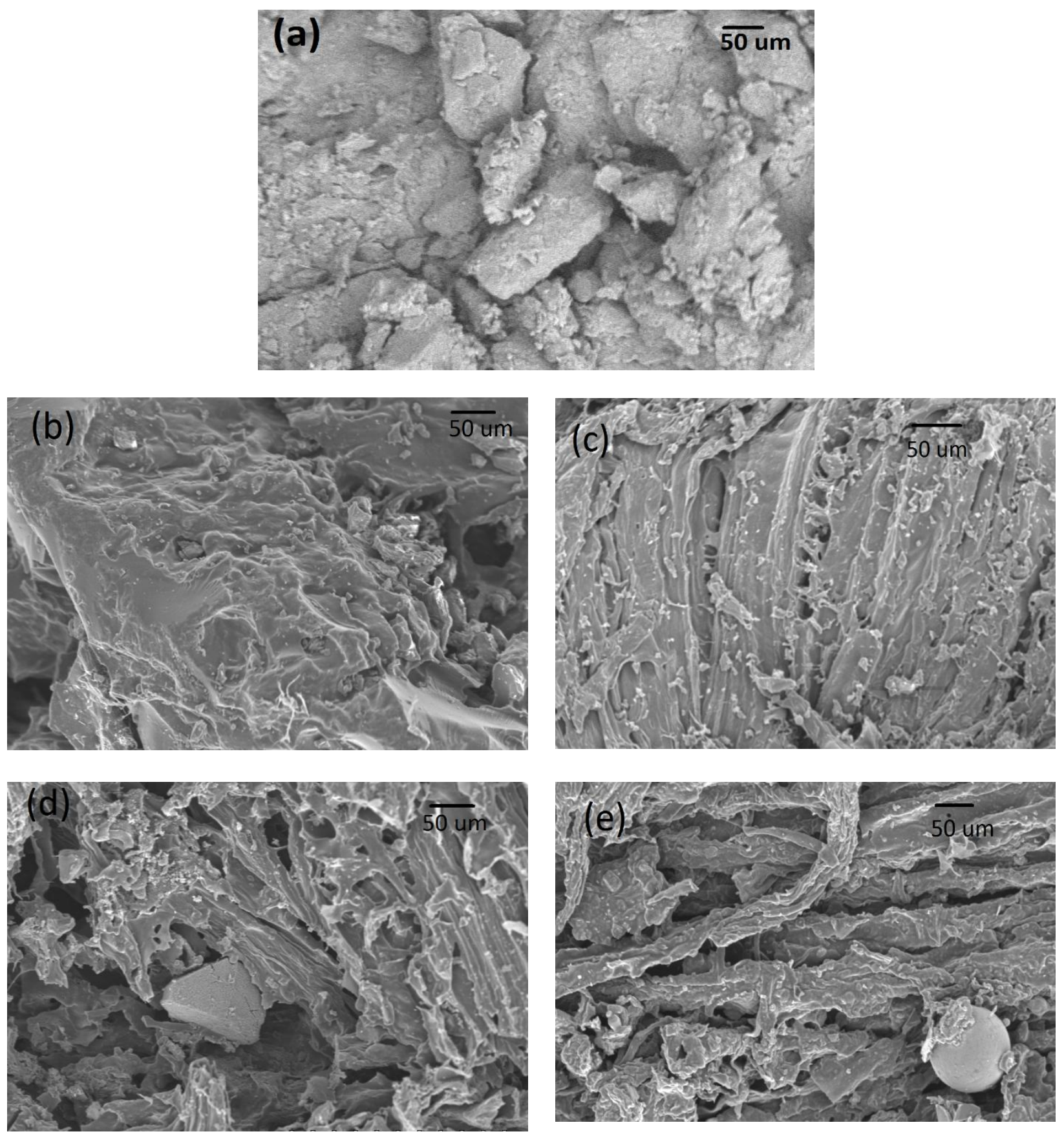

Figure 1: SEM images of: (a) Soil; (b) CE-WP1; (c) CE-WP2; and (d) CE-AWP and (e) CW-WC at magnification of 1000 

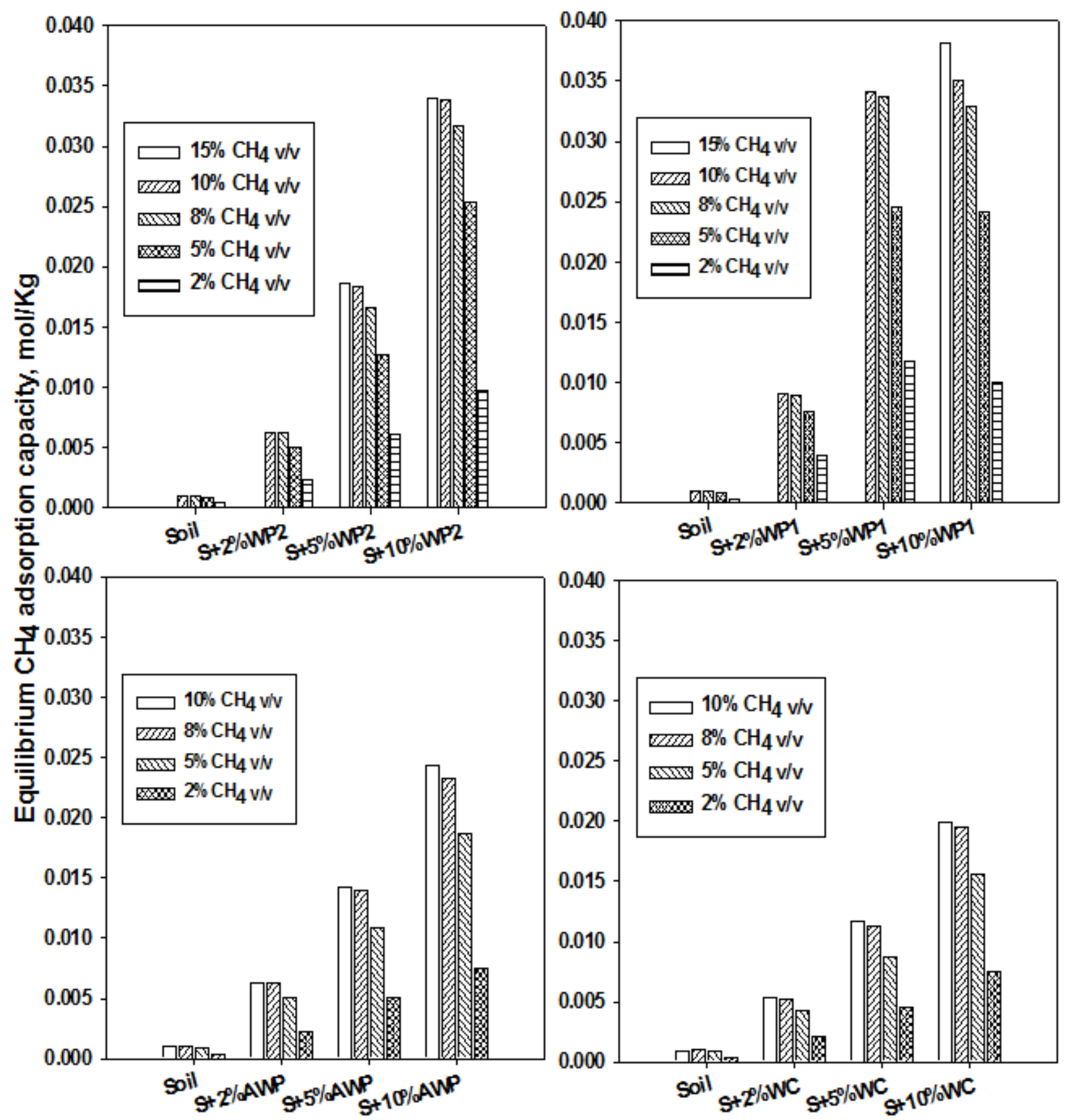

Figure 2: Equilibrium $\mathrm{CH}_{4}$ adsorption capacity of soil and biochar amended soils under dry condition 


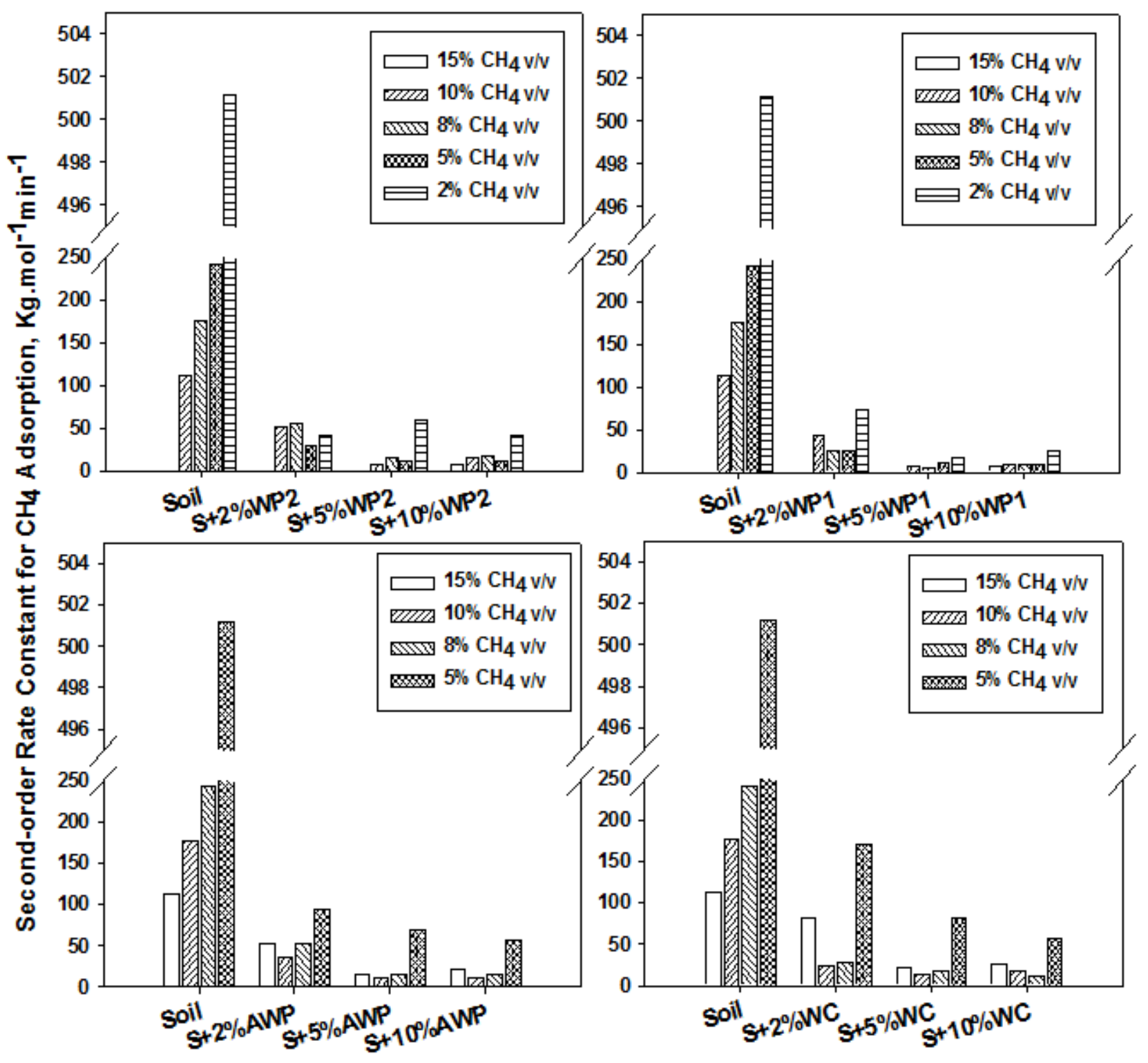

Figure 3: Kinetic rate of $\mathrm{CH}_{4}$ adsorption in soil and biochar-amended soils under dry condition 


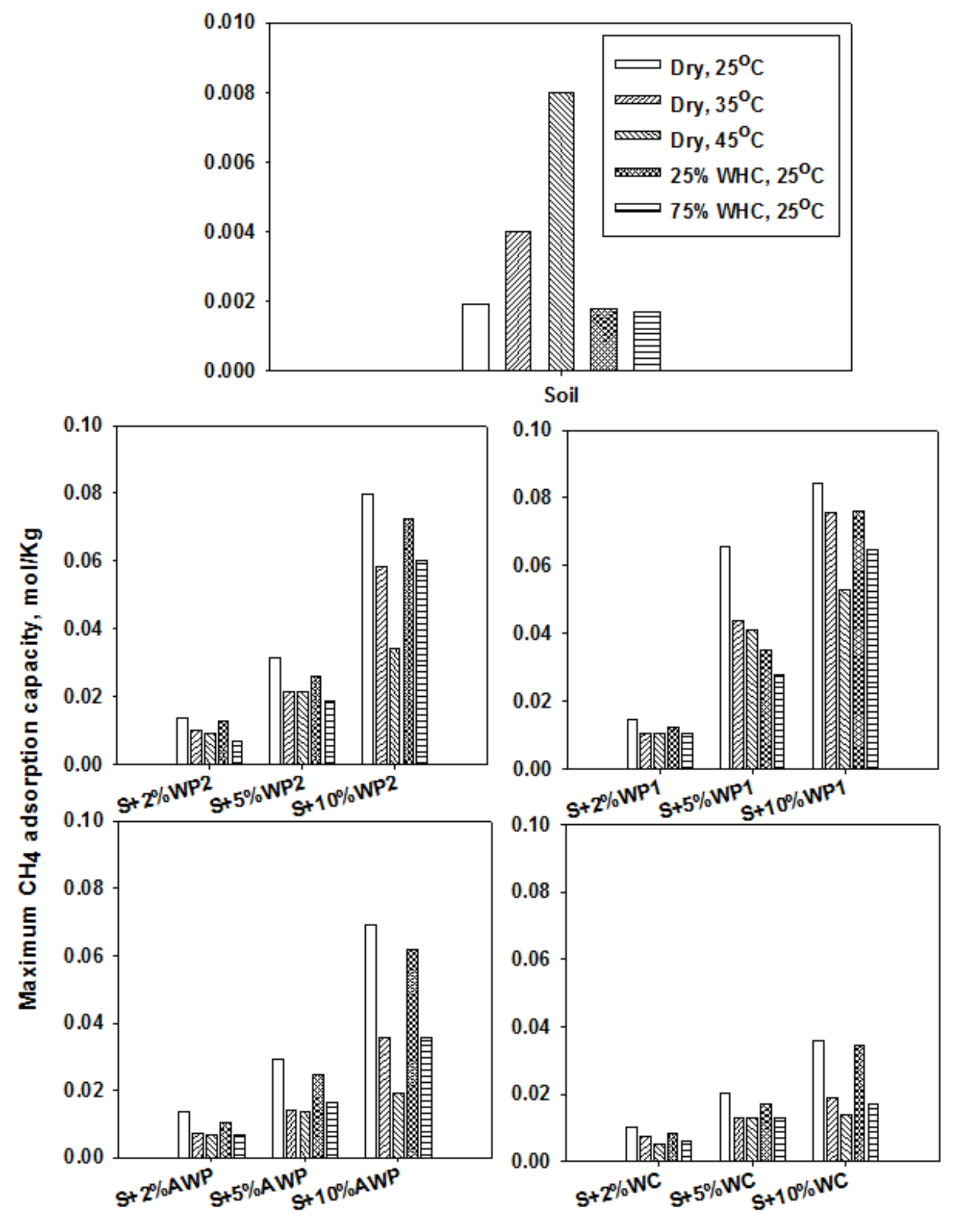

Figure 4: Effect of moisture content and temperature on maximum $\mathrm{CH}_{4}$ adsorption capacity of soil and biochar-amended soils 

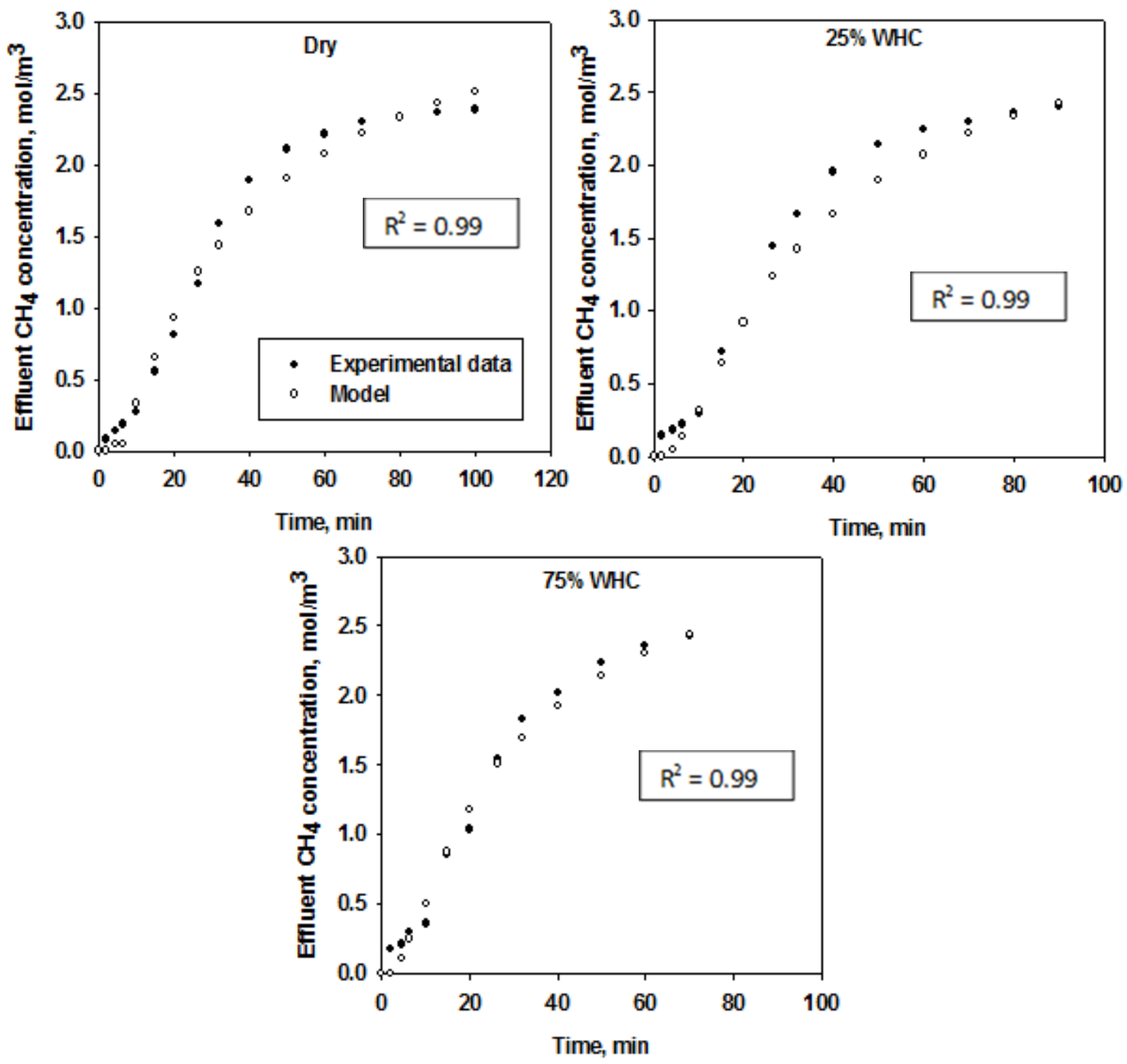

Figure 5: Comparison of experimental and modeled breakthrough curves for soil 


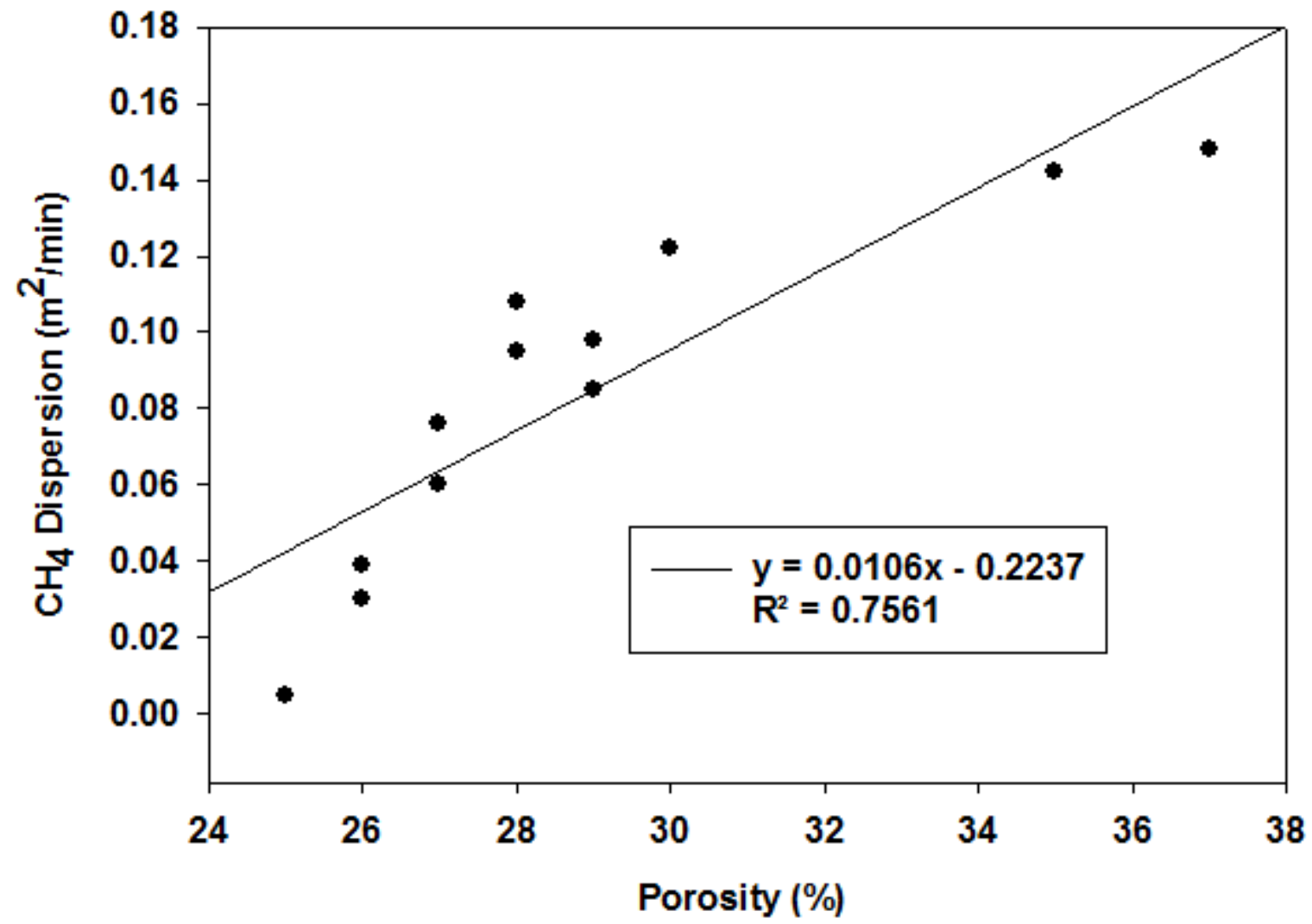

Figure 6: Correlation between $\mathrm{CH}_{4}$ dispersion coefficient and porosity of soil and biocharamended soils 